\title{
Measuring the Floor Area of Buildings: Problems of Consistency and a Solution
}

\author{
Dario Trabucco and William Douglas Miranda \\ Iuav University of Venice, CTBUH Research Office Santa Croce 191, 30135 Venice, Italy
}

\begin{abstract}
Measuring the floor area of a building may seem a straightforward activity, but it is not. What to be included and what to be considered vary in virtually every country, and definitions such as GFA (gross floor area), NRA (net rentable area), etc. are also misleading as they are not consistent. In an era in which international actors contribute for projects in all major cities, having a consistent system to measure the floor area of a building is of the utmost importance. Consistent measurements allow not just for easier and better design, but also for the comparison of buildings, as the floor area is the nominator of all parameters of sustainability, energy consumption, construction cost, occupancy ratios, cleaning fees, etc.
\end{abstract}

Key words: Floor area measurement, gross area, net area, internal dominant face.

\section{Introduction}

When building developers and designers are determining the functions and elements that are to be incorporated into a project, an equilibrium must be found between sustainable, innovative design and the tried-and-tested principles that generally dictate a financially successful project. While a glass, box-shaped, multi-story building may be an economical option to construct that maximizes the interior, usable space, this may not be the most desirable option for a tenant or owner [1].

This is especially evident in office buildings, and in the 1990's, the concept of "Sick-Building Syndrome" was recognized, which showed that deep-planned spaces that were artificially lit and conditioned had a negative effect on the health, satisfaction, and well-being of occupants [2]. In order to combat this, and create desirable, high-quality spaces, trends in building design began to incorporate more and more "green" elements, as well as exterior and shared spaces. Building developers can still be hesitant to the incorporation of new amenities to their spaces because

Corresponding author: Dario Trabucco, Ph.D., associate professor. E-mail: trabucco@iuav.it. they sacrifice the maximum amount of usable, workable space that may be possible on a site and can significantly increase building costs. That being said, the incorporation of these additional building amenities correlates directly with occupant satisfaction and the efficiency of workers in an office building, thus considerably increasing the value of the spaces. It has long been proven that this can be seen as a viable method for return on investment [3].

While these innovative and sustainable building elements are beneficial on a building-by-building or unit-by-unit basis, large governing bodies have also recognized the positives that these types of buildings have on cities as a whole and the general public, so they have seen the need to create regulations to promote good building and construction practices across entire urban realms $[4,5]$. In some cities that have recently experienced intense building growth, like Hong Kong and Singapore, adjustments to the regulations on how spaces are measured were made, in order to incentivize the construction of high-quality spaces.

These incentives can lead to cities that are more environmentally sustainable and more enjoyable for the occupants, but can lead to major global discrepancies in the value of property. As most cities 
and countries have their own unique method for measuring property, a building built in the Americas, Europe, or Asia, which, apart from the building location, may be identical and indistinguishable and can have completely different values for the amount of floor area, as a consequence of the "how" identical buildings are measured differently depending on the jurisdiction. This is especially problematic in a time when international property investment is at an all time high, not to mention the number of designers, engineers, and consultants who operate globally and all rely on the floor area calculations in their respective professions. All disciplines in the building and construction industry rely upon a project's "per-square-meter/foot" calculation as the necessary figure to compare efficiency and value. For example, property value can be measured with dollars-per-square-meter, energy efficiency can be compared with kilojoules-per-square-foot, construction speed can be analyzed by examining the number of square meters built per day, etc.

These calculations rely upon the fact that the primary figure in the analysis - the control of the study-is based off of a precise, unbiased, and unambiguous measurement, but unfortunately, this is not always the case.

\section{Problems with Existing Measurement Practices}

When measuring floor area, the regulations and practices of the local governing bodies are generally what are relied upon, but this can present major problems when a North American building has an Asian developer and a European architect, which is an example of a situation that is becoming more and more common. To further complicate matters, local floor area measurement practices generally use complicated terminology to define floor area. This includes the commonly-utilized GFA (gross floor area) or GEA (gross external area), but an immeasurable amount of other methods and terms are used including, GIA (gross internal area), NIA (net internal area), GLA (gross leasable area), NRA (net rentable area), Carpet Area, among others. While many different standards often use the same terminology, the definitions of them can be drastically different.

According to a study by JLL (Jones Lang LaSalle), a global property firm, the deviations in floor area measurements can vary up to $24 \%$, depending on the location. This can have significant impacts on the comparative analysis of properties (i.e., when comparing cost per square meter between two properties, a major difference in figures may be attributed to the regulations of the local market and not by the actual value of a space). Another major impact of these discrepancies is in the miscalculation of the maximum occupancy for space. For example, an employer may be looking for an office space that can hold 100 employees, but with a $24 \%$ discrepancy, the office space may only be suitable for 76 employees, which would have major impacts on the overall occupant comfort [6].

Furthermore, this can also have significant impacts on all building services. Specialized consultants, such as elevator and mechanical/electrical/plumbing engineers, rely on similar occupancy calculations to determine the load that their systems will have to accommodate. In overpopulated buildings, waiting time for elevators can be longer and maintenance and energy costs can increase on heating, cooling, and plumbing elements that are being overexerted and used inefficiently. Especially with increased waiting times for elevators, this can also be a major safety concern, as effective evacuation strategies in case of an emergency can be delayed. Conversely, in under-populated buildings, MEP elements and elevators can be over-designed, leading to increased costs and spaces that could have been used for working or living are now occupied by mechanical rooms or elevator shafts. These are all elements that could have been resolved with accurate and consistent measurements, but now represent significant deterrents for potential tenants. 


\section{Differences in Existing Local Standards}

In every major property market there are standards that are relied on to measure floor area, but as mentioned, this changes depending on location. The RICS (Royal Institute of Chartered Surveyors) is an international organization involved in the land, real estate, construction, and infrastructure industries, and focuses on promoting and enforcing standards and regulations. With their headquarters in London, they are the primary governing body when it comes to measuring floor area in the UK. Similar to RICS, the BOMA (Building Owners and Managers Association) International, is also recognized globally, but their focus is primarily in North America, as their headquarters are located in Washington DC and their standards for measuring buildings are recognized as the approved methodology for calculating floor area by the ANSI (American National Standards Institute). While these standards are used internationally, the specific standards of a project's respective location are generally the go-to measurement system (e.g., in Hong Kong, the Building (Planning) Regulations produced by the Hong Kong Department of Justice are used; in Australia, the Methods of Measurement produced by the Property Council of Australia are used; in Singapore, the Handbook on Gross Floor Area produced by the Urban Redevelopment Authority is used; etc.).

Within these various standards, often the first, most common - and least controversial - definition is that of GFA or GEA. This measurement is everything on a floor within a building envelope, measured to the external face of the curtain wall of a property, and while this measurement is used to help determine building costs for insurance purposes, it is also used in the early stages of the design process, when submitting building applications and approvals [7]. This represents a significant problem, as the determination of the floor area measurement can influence the design, which is unusual for a calculation that should be impartial.
An example of how local regulations can dictate design can be found when comparing the definitions between the UK and Hong Kong. In the UK, the RICS Code of Measuring Practice (6th Edition) dictates that all external open-sided balconies, canopies, parking areas, and green houses should be excluded from the measurement of GEA [8]. Conversely, in the Building (Planning) Regulations of Hong Kong, it is indicated that the area of each balcony-including the thickness of the external walls and sides of the balconies - should be included in the calculation of GFA, the equivalent measurement strategy to GEA in the UK [9]. Generally, most building regulatory bodies dictate a maximum capacity of total floor area allowable on any given site. As a result, in Hong Kong balconies were being excluded from deigns, as they would take away some of the valuable space that could be internal, workable floor area. In the UK, considering balconies would not affect the overall GEA, the decision to include or exclude them is at the discretion of the architect/developer and the decision is dictated by conventional building project design considerations (e.g., total additional construction cost, needs of the building occupants, aesthetic impact, etc.).

\section{Encouraging Good Building Practices and the Impact on Measurement Standards}

As mentioned before, there are motivating factors to create sustainable, high-quality buildings and spaces, and governing bodies have recognized the need to incentivize this for developers. Governments have made changes to the regulations for measuring floor area, with the view towards the betterment of the building and construction industry, but this process strives away from the ultimate goal of global consistency in measurement practices.

For example, the previously mentioned Building (Planning) Regulations of Hong Kong derive from the 1st Edition of the Code of Measuring Practice, which was published in 1999. Specifically in Hong Kong, there has been ever-increasing growth in building 
construction, particularly tall buildings. In 1999, there were under 100 buildings over 150 meters in Hong Kong, but now, less than 20 years later, that number has almost tripled to over 250 buildings [10]. The Hong Kong government recognized this building growth, and while the construction of green and innovative buildings was largely beneficial to the environment and local surroundings, some construction projects were not taking advantage of recycled or green building material and producing large amounts of construction and demolition waste. It was recognized that building construction was largely dictated by costs and value, and without incentives, construction of unsustainable buildings would continue to be built as long as they continued to turn a profit. Thanks to the regulations regarding the total GFA allowed on each site, there was a motivation to simply maximize the internal, usable space in a building. Consequently, in 2011, the BD (Building Department), LandsD (Lands Department), and PlanD (Planning Department) of Hong Kong published Joint Practice Note No. 1 [11] and No. 2 [12], with a view to "protect and improve the built and natural environment (through)... the construction of green and innovative buildings." The objective of the Joint Practice Notes was to "adopt a holistic life cycle approach to planning design, construction and maintenance; maximize the use of natural renewable resources and recycled/green building material; minimize the consumption of energy, in particular those non-renewable types; and reduce construction and demolition waste." As the primary strategy to achieve these objectives, the regulatory bodies indicated that, upon application and review, balconies, podiums, skygardens, and even common corridors and lift lobbies could be excluded from the total GFA measurement if they adequately incorporated green and sustainable elements.

Similar adjustments to standards were made in Singapore, in order to improve the quality of spaces. Unlike the Building (Planning) Regulations of Hong Kong, Private Enclosed Spaces and Private Roof
Terraces were already excluded from the total GFA, according the Urban Redevelopment Authority, the governing body in Singapore. As stated by the Urban Redevelopment Authority, "Balconies are important features of tropical architecture. Not only do they allow for natural ventilation and lighting, they promote healthier living and facilitates more greenery in our high-rises" [5]. This was an incentive to developers to create more space open to the sky, which would not count against the total allowable GFA. Unfortunately, it was found that developers were still measuring these spaces, and while they were not including the measurements in the GFA for planning applications, they were including them when selling on a unit-by-unit basis. As these balcony spaces are much cheaper to construct, when compared to interior, conditioned space, disproportionately large balconies - sometimes as large as $1 / 3$ of the area of any given unit-were made and would be advertised and sold to the building tenants. To combat this poor practice, the Urban Redevelopment Authority changed their rules in 2013 to cap these exterior spaces at 10\% (i.e., Private Enclosed Space, Roof Terraces, and balconies would not count against the allowed GFA on a site, as long as they remained equal to or less than $10 \%$ of the area of the attached unit). To further complicate the matter, developers could further apply for the balcony bonus GFA scheme, with approval subject to the discretion of the Urban Redevelopment.

The new rules made in Hong Kong and Singapore are effective methods to discourage poor building practices and promote and incentivize features that are environmentally sustainable and beneficial to building occupants. That being said, these rules also further complicate the measurement of floor area, especially when comparing the measurements internationally. As mentioned before, it is problematic for a mathematic calculation to effect the design considerations on a building, and now, in certain jurisdictions, this - supposedly unbiased - measurement is now at the discretion of governing bodies and depends on the 
sustainability of the project.

\section{International Standards}

In 2013, during a World Bank meeting, the IPMSC (International Property Measurement Standards Coalition) was established to develop and implement international standards for measuring floor area of property. This need for consistency in measuring floor area is recognized internationally and, now, the IPMSC is made up of over 80 professional and not-for-profit organizations from around the world.

As a way to draft and consult on these standards, the IPMSC created a Standard Setting Committee, which is an interdisciplinary group of-currently 18 - international experts who are tasked with writing and publishing the standards. The process for creating the standards can be strenuous, as each point must be unanimously agreed upon by the committee, before going through two stages of public consultation. This entire process can take over one year, but allows for insights from experts and shareholders from countries, whose local standards may contradict. Although the IPMSC was only created about five years ago, they have already published the International Property Measurement Standards for Office Buildings (released in 2014) [13], Residential Buildings (released in 2016) [14], Industrial Buildings (released in 2018) [15], and Retail Buildings (currently in the public consultation phase).

One of the first actions adopted by the Standard Setting Committee was to create new and unique terminology, in order to avoid confusion or contradictions with the previously mentions definitions used in local standards (e.g., Gross Floor Area, Net Internal Area, Carpet Area, etc.). The IPMSC defines floor area by a series of generic and instantly recognizable terms: IPMS-1, IPMS-2, and IPMS-3.

IPMS-1 relates closely to how local governing bodies define GFA or GEA: the sum of the area of each floor of a building, measured to the outer perimeter of external construction features. As a way to address the problems and discrepancies that were mentioned before, IPMS-1 specifies that open-air and unconditioned spaces, such as balconies and verandas, must be measured but have to be stated separately, clearly distinguishing the spaces. Broadly, IPMS-2 is similar to IPMS-1, but is measured to the internal dominant face (IDF, which is discussed later), instead of external construction features, and relates closely to definitions for GIA. Also, IPMS-3, which is commonly utilized to measure on a unit-by-unit basis and relates closely to definitions for NIA, excludes shared facilities, common areas, and vertical penetrations (e.g., hallways, mechanical voids, elevators shafts, etc.). In order to create further clarity in exactly the amount of space allocated to each building element, IPMS also defines "component areas", which separately state the amount of area allocated to building features such as vertical penetrations, structural elements, hygiene areas, etc.

Another term developed by IPMS is IDF, which is the defining factor in determining the IPMS-2 measurement and originated by the north-American practioners [16]. The IDF is the inside finished surface, which makes up more than $50 \%$ of the internal wall section, ignoring the presence of any columns, measured from the floor to ceiling [14]. The definition of the IDF is particularly divisive because structural columns can occupy significant amounts of valuable floor area and interior layout designs of buildings are often dictated by the placement of columns and it can become difficult to distinguish between columns and walls, especially in tall buildings where it is not uncommon for columns to reach dimensions of 5 meters in any direction. Another reason this measurement can be problematic is when measuring for IPMS-1, columns are recognized when measuring to the perimeter, exterior walls, but when measuring to the interior face for IPMS-2, they are not. Because of this discrepancy, designers may be influenced by the IPMS standards on the placement of their columns on the exterior or interior of a building, but as mentioned 
previously, this is not ideal for a calculation that is supposed to be unbiased.

Considerations such as this - and also others that inherently arise with the evolution of the building industry - are already being addressed by the Standard Setting Committee. Instead of amending previous versions of standards with clarifications and changes, these with be implemented into a single, all-encompassing document, that will be applicable for any building function, including those already addressed by IPMS (e.g., office, residential, industrial, and retail) and those that have not been considered yet (e.g., hotels, observatories, etc.). As well as expanding and spelling out some definitions, such as IDF in the IPMS-2 definition, the standards will also incorporate an IPMS-4 measurement, which will measure the usable floor space, similar to the definition of carpet area, and will generally be measured on a room-by-room basis.

\section{Acceptance of IPMS Standards}

The concept of needing an internationally recognized standard has began to gain traction, which has lead to the acceptance of the IPMSC standards in some major building markets, which is quite noteworthy considering the coalition has only existed for about five years. The first governing body to formally recognize IPMS as the official standard for measuring property was the Dubai Land Department. Not only does this incorporate an official governing body into the public consultation process, but considering Dubai is such as significant building market, this has influenced surrounding areas to also adopt IPMS. Ajman, another major city within the United Arab Emirates, has adopted the standards, and the Saudi Arabian government is consulting with shareholders to also use the standards [17].

The Middle East is a largely new tall building market, making the existing conventions and regulations newer, and thus, easier to adapt and accept the IPMS standards. With that said, there has also been a trend of established governing bodies and regulation developers that have started to adopt and accept the IPMS standards. For example, the newest publication for measurement standards by BOMA, the BOMA 2017 for Office Buildings: Standard Methods of Measurement, is now completely compatible with the IPMS Standards for Office Buildings [18].

Also, the previously mentioned Code of Measuring Practice developed by the RICS is no longer in production, and instead, RICS Property Measurement Professional Statements have been developed, with the 1st edition being published in 2016 and the 2nd in 2018. The 1st edition reflected the IPMS Standards for Offices and the 2nd was updated to also include the IPMS Standards for Residential. Furthermore, the statements indicate that they "will be updated over time to comply with other IPMS Standards, as they are published." This means that now, all jurisdictions governed by RICS must use the IPMS Standards for all building measurements, and, except in special circumstances, if a client requires a different standards, then dual-reporting is necessary [19].

Like RICS, the IPMSC recognized that the regulations for some local jurisdictions are difficult to change and some clients will demand certain regulations be used, so asked that a dual-reporting strategy be employed. This means that property can be measured by utilizing any preferred method of measurement, but should also use IPMS to serve as the "mediator", in order to compare measurement with other properties and provide a clearly defined and distinct value (i.e., if a client asks for the GFA of a property, there are countless measurement strategies to use, but if they ask for the IPMS-1, there is only one, clear measurement strategy to use). This is the strategy that is suggested by the API (Australian Property Institute). In Australia, while most properties require the PCA (Property Council of Australia) Methods of Measurement, the API recommends a dual-reporting strategy be used with IMPS, as they state that "in time the API expects, with Member support, IPMS will 
become the primary basis of measurement across markets" [20].

\section{Conclusions}

The receptiveness of international property markets to accept and integrate IMPS standards represents the necessity for globally-accepted rules when it comes to measuring floor area. There is still progress to be made, both in the development and expansion of the standards themselves and the further acceptance of them across all markets. With the promotion of a dual-reporting strategy, the standards can be easier to encourage the use of new standards. Local regulations can continue to be used by developers, for building applications, and by governing bodies, for a strategy to incentivize good building practices. Alternatively, the IPMS standards can be utilized as an unambiguous, unbiased mathematical calculation that is needed to ensure the success of buildings. Not only will is serve as the appropriate measure for comparing properties across a developers portfolio, but-perhaps more importantly-serve as the necessary figure for the activities of various building consultants (e.g., elevator and MEP engineers can now determine an accurate measurement for the loads on their systems, safety consultants can determine the maximum occupancy of any floor or space).

Any person involved in the building industry, whether a developer, designer, or future occupant, can simply ask for the IPMS 1, 2, 3, or 4 measurements, and clearly know exactly what is and is not being included in the space that they are constructing, designing, or buying. The IPMS Standards represent a method that is not only consistent and clear, but fully repeatable across time and location. This can guarantee confidence for investors and potential tenants in their potential properties, as well as create an area of stability in a property market that is constantly expanding and fluctuating.

\section{References}

[1] Buchanan, P. 2007. "The Tower: An Anachronism
Awaiting Rebirth?" Harvard Design Magazine: New Skyscrapers in Megacities on a Warming Rise 26: 1-5.

[2] Gou, Z., and Lau, S. 2012. "A Survey of Sick Building Syndrome: Workplace Design Elements and Perceived Indoor Environmental Quality." In Proceedings of 10th International Conference on Healthy Buildings, 658-63.

[3] Myers, G., and Reed, R. 2007. "The Business Case for Sustainable Office Buildings." Paper presented on Sustainable Building Conference of Transforming our Built Environment, Aukland.

[4] Joint Practice Notes on Protection and Improvement of the Built and Natural Environment. JPN 1 and JPN 2. 2011. Hong Kong: Buildings Department, Lands Department and Planning Department.

[5] Handbook on Gross Floor Area. 2018. Singapore: Urban Redevelopment Authority.

[6] Hall, T. 2016. "Code of Measuring-International Property Measurement Standards." www.jllvantagepoint.com.

[7] Cartlidge, D. 2017. Quantity Surveyor's Pocket Book (3rd ed.). Abingdon: Routledge.

[8] Code of Measuring Practice. 2007. 6th ed. Coventry: Royal Institution of Chartered Surveyors (RICS).

[9] Building (Planning) Regulations. Cap. 123F, section 38. 2018. Hong Kong: Hong Kong Department of Justice.

[10] skyscrapercenter.com. 2018. The Skyscraper Center. Chicago: The Council on Tall Buildings and Urban Habitat (CTBUH). [online] Available at: http://www.skyscrapercenter.com/.

[11] Buildings Department, Lands Department, Planning Department Joint Practice Note No. 1 Green and Innovative Buildings. 2011. https://www.bd.gov.hk/eng lish/documents/joint/JPN01.pdf.

[12] Buildings Department, Lands Department, Planning DepartmentJoint Practice Note No. 1 Second Package of Incentives to Promote Green and Innovative Buildings. 2011. https://www.bd.gov.hk/english/documents/joint/JP N02.pdf.

[13] International Property Measurement Standards: Office Buildings. 2014. London: International Property Measurement Standards Coalition (IPMSC). https://ipmsc.org/standards/office/.

[14] International Property Measurement Standards: Residential Buildings. 2016. London: International Property Measurement Standards Coalition (IPMSC). https://ipmsc.org/standards/residential/.

[15] International Property Measurement Standards: Industrial Buildings. 2018. London: International Property Measurement Standards Coalition (IPMSC). https://ipmsc.org/standards/industrial/.

[16] ASTM E 1836-08 Standard Practice for Building Floor 
Area Measurements for Facility Management. 2008.

[17] Jackson, R. 2016. “In Equal Measure.” RICS Property Journal July/August: 12.

[18] BOMA 2017 for Office Buildings: Standard Methods of Measurement. ANSI/BOMA Z65.1. 2017. Washington, DC: Building Owners and Managers Association (BOMA)
International.

[19] RICS Property Measurement: Professional Statement, Global. 2018. 2nd ed. London: Royal Institute of Chartered Surveyors (RICS).

[20] Technical Information Paper-Methods of Measurement. 2018. Deakin: The Australian Property Institute. 